\title{
Mechanisms of drought resistance in introgression forms of Lolium multiflorum/Festuca arundinacea
}

\author{
D. PERLIKOWSKI* and A. KOSMALA \\ Institute of Plant Genetics, Polish Academy of Sciences, 60-479 Poznan, Poland
}

\begin{abstract}
Drought resistance in plants can be associated with four different strategies to cope with water stress. These strategies are classified as drought escape, avoidance, tolerance, and recovery. The expression of each strategy depends on plant species and its genetic potential, but also on the environmental conditions, including the stress intensity and duration. Often, prolonged drought conditions are associated with drought escape or avoidance, whereas short but severe drought periods induce drought tolerance. To analyze the components of drought resistance in forage grasses, we applied two Lolium multiflorum/Festuca arundinacea introgression forms into a comprehensive research. Obtained results clearly show that the response of plants to severe short term drought conditions with limited rhizosphere did not reflect their response to long progressive drought conditions, which did not limit root growth. The BC4-INT-40 introgression form with extensive and deep roots was characterized by a more efficient drought avoidance and regeneration mechanisms under long-term drought, whereas the BC4-INT-66 form with shorter roots revealed a lower productivity and re-growth capacity under the prolonged drought. On the other hand, this form had also a better photosynthetic performance under short and intensive drought conditions with a limited space for root development.
\end{abstract}

Additional key words: drought avoidance, drought tolerance, osmoprotectants, photosynthesis, phytohormones, recovery.

\section{Introduction}

Plants in areas with a temperate climate are frequently affected by events of water deficit, occurring during vegetative as well as reproductive growth. Drought is one of the main environmental factors responsible for reduction of plant yield (Bray et al. 2000). Drought resistant plant species are able to modify their morphology and metabolism in order to survive drought periods and to restore normal functioning after the stress cessation (Dos Reis et al. 2012). Among plant reactions to water deficit, associated with drought resistance, several different strategies can be specified: 1) drought escape, which relies on the synchronization of plant life cycle with the seasonal drought, and the termination of plant vegetative growth before stress conditions occur, 2) drought avoidance, responsible for rearrangements in plant morphology as well as in cellular metabolism (e.g., development of deeper root systems, stomatal closure, and leaf rolling) to avoid/reduce water deficit in plant organs and tissues, especially during prolonged stress conditions, 3) drought tolerance, associated with the induction of remodeling of cellular metabolism to reduce cellular damage, caused by water deficit in plant tissues, usually under short-term but severe periods of drought, and 4) drought recovery, which determines the plant capacity to regenerate metabolism after the stress cessation (McCue and Hanson 1990). Under short-term drought, the plant's ability to tolerate stress conditions plays the most significant role, since it allows maintenance of the photosynthetic reactions in plant tissues, mainly in leaves. To accomplish this aim, the plant needs to maintain the cellular homeostasis during the absence of sufficient water supply. This can be achieved by a remodeling of cellular biochemistry, including the fixation of membrane lipid composition in order to reduce damage of cellular membranes and to maintain their functions ( $\mathrm{Yu}$ and $\mathrm{Li} 2014$ ), or by a synthesis of several, different in origin, chemical compounds, such as: specific sugars, alcohols, or amino acids, which can increase cell osmotic potential, protecting cellular environment from a dehydration and maintaining the activities of enzymes (Yancey 2005). However, during prolonged water limitations, those modifications in plant metabolism are not enough to keep the plant alive; thus,

Submitted 27 February 2020, last revision 29 April 2020, accepted 19 May 2020.

Abbreviations: ABA - abscisic acid; RWC - relative water content.

* Corresponding author; e-mail: dper@igr.poznan.pl 
other adjustments are required to adapt plants to these adverse environmental conditions including morphology and metabolism of plant root system (Farooq et al. 2009). Very often, even the development of deep and extensive root system is not sufficient to supply the plant with water and severe damage or even death can occur. Some plant species have developed the ability to efficiently regenerate their damaged tissues or to re-grow new organs after stress cessation.

Grass species from Lolium (ryegrass) and Festuca (fescue) genera, often named as the Lolium-Festuca complex, are the most important forage grasses, cultivated in the temperate climate zone. These grass species are characterized by numerous complementary agronomic traits (Thomas and Humphreys 1991). For example, L. multiforum Lam. (Italian ryegrass), one of the most important forage grass species cultivated in Europe, is characterized by a high forage quality and productivity under comfortable growing conditions, but also by a low resistance to environmental stresses, such as water deficit, low temperature, or soil salinity (Humphreys and Thomas 1993). On the other hand, F. arundinacea Schreb. (tall fescue) has the ability to avoid water deficit conditions, possessing a high potential for developing a deep and extensive root system (drought avoidance strategy). This species is able to tolerate water deficit conditions, reprogramming its cellular metabolism in different organs, including leaves (drought tolerance strategy). However, $F$. arundinacea is not as good as L. multiflorum in terms of forage quality and productivity under comfortable environment conditions (optimal air temperature and soil hydration) (Humphreys and Thomas 1993, Kosmala et al. 2012). Interestingly, L. multiflorum $(2 \mathrm{n}=4 \mathrm{x}=28)$ and $F$. arundinacea $(2 \mathrm{n}=6 \mathrm{x}=42)$ can be crossed with each other to create partially fertile $F_{1}$ pentaploid $(2 n=$ $5 \mathrm{x}=35) F$. arundinacea $\times$ L. multiflorum hybrids. This phenomenon gives a possibility to transfer of different components of drought resistance from $F$. arundinacea to $L$. multiflorum by backcrossing of pentaploid hybrid to diploid or tetraploid cultivars of L. multiflorum, and to dissect drought resistance to its different components, present in different introgression forms (Perlikowski et al. 2014, 2016a,b 2019).

In this review, we demonstrate the results of the research, performed during the last few years by our scientific team, on two tetraploid $L$. multiflorum $/ F$. arundinacea introgression lines, $\mathrm{BC}_{4}$-INT-40 (primary named as 4/10) and $\mathrm{BC}_{4}$-INT-66 (primary named as $7 / 6$ ), with respect to their ability to express different strategies of drought resistance, depending on the environmental conditions of growth.

\section{Drought avoidance is a crucial survival strategy during mild and prolonged periods of water deficit particularly in conditions, which do not limit a development of plant roots}

Plants growing under comfortable field conditions are usually not limited by the soil area to produce an extensive root system to supply the photosynthetic organs with sufficient amounts of water. However, under prolonged drought, a decreasing soil water potential influences firstly the roots and can stimulate root elongation growth in order to search water source in deeper soil layers, which is the most important attribute of drought avoidance strategies (Verslues et al. 2006). Thus, simulated field conditions seem to be perfect to analyze a plant's potential for drought avoidance. One possible approach is the subjection of plants to grow under 'rainout shelters', which successively protect the experimental area from rainfall and simultaneously do not affect other environmental parameters, such as air temperature (Perlikowski et al. 2014). However, it is rather difficult to analyze the parameters associated with root development under field conditions. Thus, experiments under 'rainout shelters' are usually used to select plants with respect to their capacity to avoid drought, but the root systems of the selected plants are further analyzed using different experimental strategies, e.g., a system of tubes filled with soil placed in a phytotron or a glasshouse.

Experiments in the field: In the first step of our research, a plant selection with respect to drought resistance was performed. Population of 35 randomly selected $\mathrm{BC}_{4}$ tetraploid L. multiflorum/F. arundinacea introgression forms were subjected to 14 weeks of progressive water deficit conditions under 'rainout shelters', followed by two weeks of re-watering (Perlikowski et al. 2014). Clones of each genotype were divided between three 'rainout shelters' with simulated drought conditions and one 'irrigated shelter' in the field. Plants were evaluated according to four traits: bonitation, dry and fresh matter mass, and re-growth after cut at four time-points: before drought initiation, after 4, 10, 14 weeks of drought, and 2 weeks after initiation of re-watering. Under water deficit conditions, the $\mathrm{BC}_{4}$-INT-40 form revealed the best yield with respect to its dry and fresh biomass. The values of yield parameters for this introgression form were comparable to the values revealed for control plants under non-stress conditions. On the other hand, the $\mathrm{BC}_{4}$-INT-66 form demonstrated a significantly lower yield under water deficit conditions, compared to the control conditions, and to the $\mathrm{BC}_{4}$-INT-40 form under drought period. Interestingly, the dry and fresh biomass of $\mathrm{BC}_{4}$-INT-66 form were even higher under control conditions, compared with the $\mathrm{BC}_{4}$-INT-40 form (Perlikowski et al. 2014). Thus, we hypothesized that drought avoidance could be the main survival strategy under analyzed environmental conditions in the $\mathrm{BC}_{4}$-INT-40 form. However, the other components of drought resistance could be also important for this introgression form. Furthermore, we also hypothesized that the $\mathrm{BC}_{4}$-INT-40 form was able to produce a deeper and more extensive root system under prolonged conditions of water deficit, which was the main trait responsible for the capacity of drought avoidance in this introgression form. To prove these hypotheses we performed another sets of experiments on the selected plants, using 'a pot system' to evaluate drought tolerance and 'a tube system' to evaluate drought avoidance under simulated water deficit in the 
analyzed plants. Although, the experiments in pots were performed following the field study (Perlikowski et al. 2014), we decided in this review to discuss first the later work performed in tubes (Perlikowski et al. 2019).

Experiments in a 'tube system': For more detailed evaluation of root morphology and metabolism under water deficit conditions, a tube system was shown to be more suitable, since it allowed an extensive root growth and simultaneously an easier extraction of intact roots from soil for further biochemical and molecular analyses (Perlikowski et al. 2019). In this approach, the selected introgression forms, $\mathrm{BC}_{4}$-INT-40 and $\mathrm{BC}_{4}$-INT-66, were subjected to progressive water deficit for $64 \mathrm{~d}$ followed by $14 \mathrm{~d}$ of re-watering, to analyze the contribution of their root systems in a different capacity of drought avoidance (Perlikowski et al. 2014). Multiple clones of each genotype were planted into separate $1 \mathrm{~m}$ long tubes filled with the mixture of sand and Vermiculite and watered for $28 \mathrm{~d}$ with Long-Ashton (Garczyński and Garczyńska 2007) nutrient solution. After that, watering was stopped in half of the tubes and plants were subjected for progressive water deficit, other half of the plants (controls) were watered until end of experiment. The plants were grown in the greenhouse under natural irradiance and photoperiod, day/ night temperatures $\sim 25 / \sim 17^{\circ} \mathrm{C}$, and a $\sim 60 \%$ air humidity. Roots and leaves were collected at five time-points of experiment: $1 \mathrm{~d}$ before drought, after 7, 21, and $64 \mathrm{~d}$ of drought, and $14 \mathrm{~d}$ after re-watering. We analyzed: root and leaf morphological parameters, leaf relative water content (RWC), water content, electrolyte leakage, gas exchange, chlorophyll fluorescence, hormones accumulation, and root metabolism (accumulation of primary metabolites and membrane lipids). The progression of drought was relatively gradual, to allow the plants to adapt for changing environmental conditions in tubes. Moreover, after $64 \mathrm{~d}$ of water deficit, the water was still accessible to be extracted by roots from the bottom of the tubes.

Under given conditions, morphology of shoots and roots was disturbed by the stress conditions, in both analyzed introgression forms, however, clear differences were observed between the $\mathrm{BC}_{4}$-INT-40 and $\mathrm{BC}_{4}$-INT-66 forms. The most important difference was associated with the morphological characteristics of the root system, which, in our opinion, had a significant influence on the physiological parameters. The $\mathrm{BC}_{4}$-INT-40 form, starting from the $21^{\text {st }}$ day of water deficit, was characterized by a significantly better development of the roots, including higher number, dry mass, and average length of roots, compared with the $\mathrm{BC}_{4}$-INT-66 form. Furthermore, the maximum root length reached almost the maximum capacity of the tubes after $64 \mathrm{~d}$ of water deficit, and the most distant roots were characterized by the presence of short root tip hairs, which might improve water uptake, only in the $\mathrm{BC}_{4}$-INT-40 form (Fig. 1a). Also, metabolism of the root cells changed during the experiment and clear differences between the analyzed introgression forms were observed. A significantly higher accumulation of sucrose and glucose was noticed in the form $\mathrm{BC}_{4}$-INT- 40 on the $64^{\text {th }}$ day of water deficit, and this phenomenon could have been associated with the reposition of energy resources to the roots and might have a significant impact on the higher capacity of this introgression form to develop roots (Fig. 1b). Moreover, the highly accumulated saccharides together with a higher accumulation of proline in roots of the $\mathrm{BC}_{4}$-INT- 40 form on the $64^{\text {th }}$ day of water deficit, could also decrease the root osmotic potential, thereby increasing the root capacity to water uptake (Fig. 1c) (Perlikowski et al. 2019). A better root performance under drought conditions in the $\mathrm{BC}_{4}$-INT-40 form could have been also related to the early remodeling of root membrane lipids, which consequently could have had a significant impact on a higher stability of root membranes in a dehydrated state, resulting in a better root functioning under such the conditions (Fig. 1d). These differences in the root parameters observed between the analyzed introgression forms influenced significantly the functioning of aboveground parts of plants, and had the reflection in the differences in the physiological parameters, describing performance of shoots in two analyzed introgression forms. Thus, the introgression form $\mathrm{BC}_{4}$-INT-40 also had lower leaf membrane damage under drought conditions and higher shoot biomass, compared to the $\mathrm{BC}_{4}$-INT-66 form (Fig. 1a,e). It has been already recognized that the shoot and root growth parameters are under hormonal control, since abscisic acid (ABA) accumulation was proved to significantly inhibit shoot growth and stimulate root development under water deficit conditions (Kang and Zhang 2004, Alvarez et al. 2008). Simultaneously, drought was shown to have a negative impact on the accumulation of other plant hormones including auxins and cytokinins (Schachtman and Goodger 2008). Both introgression forms, $\mathrm{BC}_{4}$-INT-40 and $\mathrm{BC}_{4}$-INT-66, exhibited a similar increase of $\mathrm{ABA}$ content during progression of water deficit, but the $\mathrm{BC}_{4}$-INT-40 revealed a slightly higher accumulation of ABA in leaves on the $64^{\text {th }}$ day of water deficit which might influence root lipid remodeling in this form (Fig. 1f) (Golldack et al. 2014). The accumulation of auxins and cytokinins could be also important for increased shoot and root development in $\mathrm{BC}_{4}$-INT-40 form (Fig. $1 g$ ) since in roots, zeatine and indole-3-acetic acid content was stable compared to control and leaves; indole-3-acetic acid content even increased under drought, however, not all the observed differences among the analyzed introgression forms were statistically significant (Perlikowski et al. 2019).

To sum up this part of our review, we conclude that by the applying 'a tube system' to simulate drought conditions, we succeeded to prove that two analyzed introgression forms, $\mathrm{BC}_{4}$-INT-40 and $\mathrm{BC}_{4}$-INT-66, selected in the field conditions as plants with a different capacity to avoid drought, had in fact, a different capacity to develop deep and extensive roots under prolonged drought conditions. This differentially expressed drought avoidance strategy was also, at least partially, associated with differences in root metabolism, observed between the analyzed introgression forms. 


\section{Drought tolerance can be a crucial survival strategy during short-term but severe water deficit especially when plant root development is limited}

The research on plant drought tolerance is usually focused on leaf physiology and metabolism under stress conditions, when plants are subjected to simulated, severe water deficit in pots with limited root growth and development. In such conditions, the amount of water used by plants is strictly controlled. Soil water deficit, which strongly affects water content in leaves, results in their wilting in a relatively short time. Usually, this type of stress is lethal for plants during longer periods of stress duration. Thus, to evaluate the potential of drought tolerance for the $\mathrm{BC}_{4}-\mathrm{INT}-40$ and $\mathrm{BC}_{4}$-INT-66 forms, with respect to their leaf metabolism, the previously selected plants were subjected to short- term drought treatment (Perlikowski et al. 2014). Clones of each genotype were transferred to $1.75-\mathrm{dm}^{3}$ pots with exact amount of soil. Pots were weighted and equalized during the whole experiment to maintain the same level of soil humidity between the clones and genotypes. This trail was performed under controlled phytotron conditions with a day/night temperatures of $22 / 17^{\circ} \mathrm{C}, 16-\mathrm{h}$ photoperiod, an irradiance of $200 \mu \mathrm{mol} \mathrm{m} \mathrm{m}^{-2} \mathrm{~s}^{-1}$, and a $30 \%$ air humidity. The experiment lasted for $21 \mathrm{~d}$ and was divided into $11 \mathrm{~d}$ of drought and $10 \mathrm{~d}$ of re-watering. All the measurements were performed at the same time of day at five selected time-points: before drought, after 3, 6, and $11 \mathrm{~d}$ of drought and $10 \mathrm{~d}$ after re-watering. During this trial we analyzed: RWC, water content, electrolyte leakage, gas exchange, chlorophyll fluorescence, and accumulation of proteins, primary metabolites, and membrane lipids.

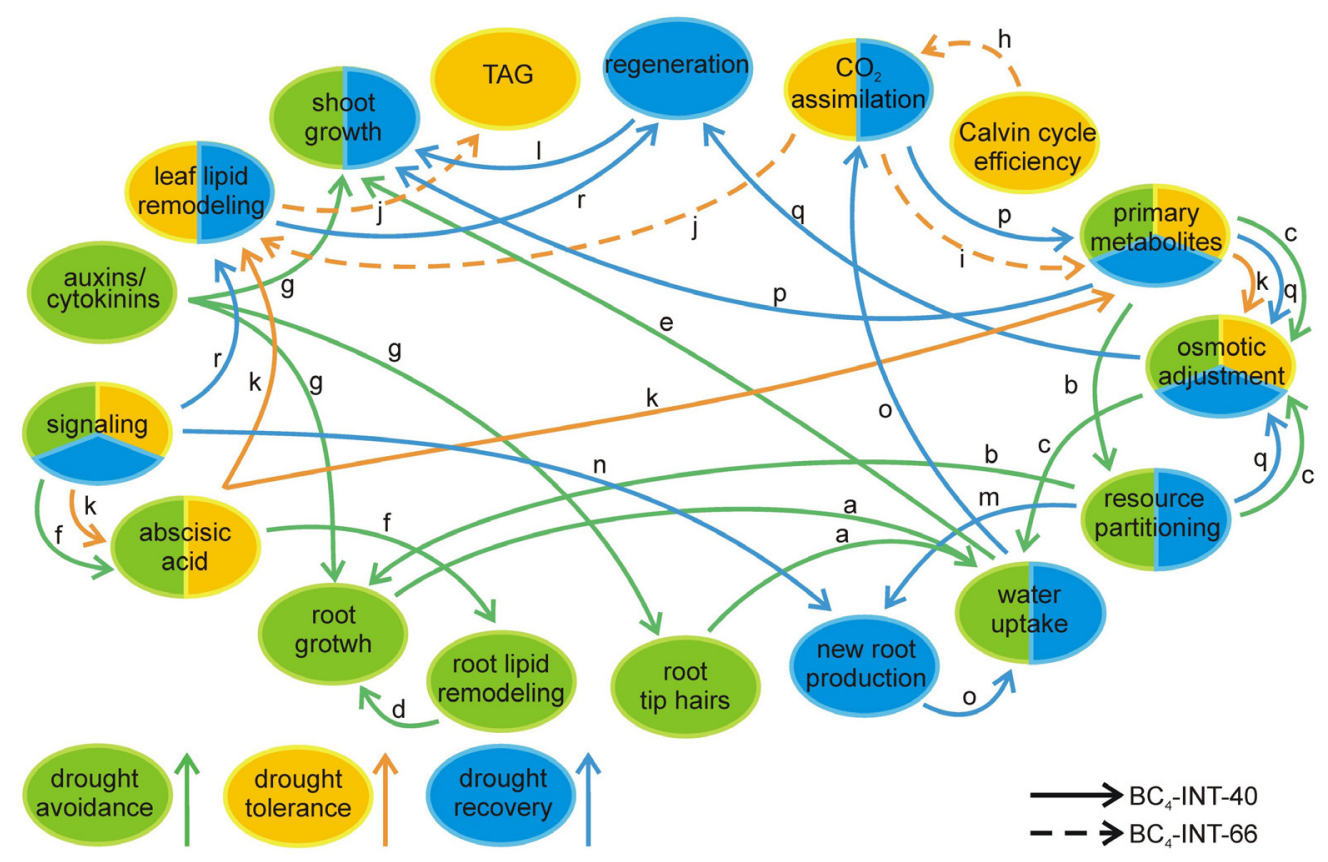

Fig. 1. A comprehensive scheme of reactions in analyzed introgression forms in response to water deficit conditions: $a$ - a more intensive root growth of the $\mathrm{BC}_{4}$-INT-40 form improves water uptake under drought conditions (Perlikowski et al. 2019); $b$ - a reposition of saccharides to roots in the $\mathrm{BC}_{4}$-INT-40 form under drought influences root development (Perlikowski et al. 2019); $c$ - accumulated osmoprotectants decrease osmotic potential of roots in the $\mathrm{BC}_{4}$-INT-40 form (Perlikowski et al. 2019); $d$ - an early remodeling a root membrane lipidome enhances root functioning under drought in the $\mathrm{BC}_{4}$-INT-40 form (Perlikowski et al. 2019); $e$ - an increased water uptake in the $\mathrm{BC}_{4}$-INT-40 form has a positive impact on shoot growth under drought (Perlikowski et al. 2019); $f$ - an improved stress signaling and a higher abscisic acid content in the $\mathrm{BC}_{4}$-INT-40 form under drought influence root lipid composition (Perlikowski et al. 2019); $g$ - stable amounts of auxins and cytokinins in the $\mathrm{BC}_{4}$-INT-40 form are responsible for growth and morphological modifications of roots and shoots under drought (Perlikowski et al. 2019); $h$ - a higher efficiency of the Calvin cycle in the BC B $_{4}$-INT-66 form under drought is associated with a higher $\mathrm{CO}_{2}$ assimilation rate (Perlikowski et al. 2014); $i$ - the $\mathrm{BC}_{4}$-INT-66 form with a higher photosynthetic rate accumulates higher amounts of primary metabolites (Perlikowski et al. 2016a); $j$ - a higher carbon assimilation rate in the $\mathrm{BC}_{4^{-}}$ INT-66 form has also an impact on lipid metabolism and accumulation of triacylglycerol (TAG) lipids under drought (Perlikowski et al. 2016b); $k$ - an early remodeling a leaf membrane lipidome and a more intensive accumulation of osmoprotectants in leaves of the $\mathrm{BC}_{4}$-INT-40 form under drought are associated with efficient stress signaling (Perlikowski et al. 2016a,b); $l$ - the regeneration ability of the $\mathrm{BC}_{4}$-INT-40 form has a significant impact on re-growth capacity after stress cessations (Perlikowski et al. 2014); $m$ - a higher accumulation of primary metabolites in roots after re-watering enhances a new root development in the $\mathrm{BC}_{4}$-INT-40 form (Perlikowski et al. 2019); $n$ - a new root production could be at least partially associated with more efficient signaling in the BC $\mathrm{BC}_{4}-\mathrm{INT}-40$ form (Perlikowski et al. 2016b, 2019); o - new roots increase water uptake and photosynthetic capacity of the BC $\mathrm{B}_{4}$-INT-40 form during recovery (Perlikowski et al. 2019); $p$ - an enhanced photosynthesis of the $\mathrm{BC}_{4}$-INT-40 form after re-watering has a positive impact on re-growth capacity (Perlikowski et al. 2014); $q$ - a higher membrane regeneration capacity of the $\mathrm{BC}_{4}$-INT-40 form after stress cessation is associated with accumulation of osmoprotectants (Perlikowski et al. 2016a); $r$ - an enhanced signaling the environmental changes might be responsible for faster membrane lipid remodeling and regeneration ability in the $\mathrm{BC}_{4}$-INT-40 form (Perlikowski et al. 2016b). 
During these studies, we focused on the performance of photosynthesis, which was proved to be very sensitive to water deficit conditions (Munns 2002). The inhibitory effect of severe drought on photosynthesis may be associated either with the low availability of $\mathrm{CO}_{2}$, resulting from reduction of gas diffusion through stomata (stomatal regulations), and from reduction of carbon metabolism (non-stomatal regulations) (Flexas et al. 2004, Flexas and Medrano 2001). Metabolic limitations of carbon metabolism under drought stress can be related mainly to the inhibition, or at least, to the reduced activity of essential enzymes of the Calvin cycle, responsible for $\mathrm{CO}_{2}$ assimilation (Ma et al. 2008, Lawlor 2009, Uematsu et al. 2012).

There were no significant differences between the $\mathrm{BC}_{4}$ INT-40 and $\mathrm{BC}_{4}$-INT-66 forms, with respect to their leaf RWC and to membrane damage on the $11^{\text {th }}$ day of water deficit in pots. The RWC and membrane integrity similarly decreased in both introgression forms. On the other hand, the $\mathrm{BC}_{4}$-INT-66 form was characterized by a higher $\mathrm{CO}_{2}$ assimilation rate on the $11^{\text {th }}$ day of water deficit, compared to the $\mathrm{BC}_{4}$-INT-40 form. Interestingly, both introgression forms decreased similarly stomatal conductance under water deficit, which consequently resulted in a reduction of transpiration rate in these plants compared with the controls. However, with the same stomatal conductance, the form $\mathrm{BC}_{4}$-INT-66 was also characterized by a higher $\mathrm{CO}_{2}$ assimilation rate (Perlikowski et al. 2014), associated to a high probability with a higher efficiency of the Calvin cycle in this form (Fig. 1h). In fact, our further comprehensive proteomic study revealed that the $\mathrm{BC}_{4}$ INT-66 form demonstrated a higher accumulation and activity of chloroplast fructose 1,6 bisphosphate aldolase under drought and control conditions (Perlikowski et al. 2014, 2016a). Photosynthesis is the main source of compounds required for synthesis of sugars, amino acids, and others important for plant growth and development (Dolferus 2014). Thus, the reduction of photosynthesis reflects in inhibition of growth, biomass production, and metabolite accumulation (Chaves et al. 2010). The introgression form $\mathrm{BC}_{4}$-INT-66, with a higher photosynthetic efficiency under drought conditions, was simultaneously characterized by a significantly higher accumulation of several primary metabolites, including glucose in leaves (Fig. 1i) (Perlikowski et al. 2016a). Moreover, also a higher accumulation of triacylglycerol lipids was found in the $\mathrm{BC}_{4}$-INT-66 form during drought period (Perlikowski et al. 2016b). Triacylglycerol lipids can act as energy storage compounds in forage grasses and their higher accumulation might be associated with a higher photosynthetic activity observed in the $\mathrm{BC}_{4}$ INT-66 form (Perlikowski et al. 2014, 2016a,b). On the other hand, we also recognized that $\mathrm{BC}_{4}$-INT-40 form in short-term drought conditions was characterized by a significantly faster response to water deficit by remodeling of the leaf membrane lipids composition and accumulating higher amounts of osmoprotectants (Fig. 1k) (Perlikowski et al. 2016a,b); those reactions are under control of ABA (Golldack et al. 2014). This might indicate a better stress signaling in this form which was also supported by a faster response of root development observed in the $\mathrm{BC}_{4}$-INT-40 form in tubes trial (Perlikowski et al. 2019).

To sum up this part of our review, we conclude that in the environment with a limited space for root development, two analyzed introgression forms selected earlier in the field conditions, $\mathrm{BC}_{4}-\mathrm{INT}-40$ and $\mathrm{BC}_{4}-\mathrm{INT}-66$, revealed a similar rate of tissue dehydration and cellular membrane damage. However, the efficiency of photosynthesis in the $\mathrm{BC}_{4}$-INT-66 form was higher under drought conditions, due to a higher efficiency of the Calvin cycle, associated with a higher accumulation and activity of chloroplast aldolase. This phenomenon was accompanied by a higher accumulation of some primary metabolites and storage lipids in the $\mathrm{BC}_{4}$-INT-66 form. On the other hand, all results presented in the set of our papers (Perlikowski et al. 2014, 2016a,b, 2019) revealed that the strategy of drought tolerance could not be as crucial to survive prolonged drought conditions in the field compared to drought avoidance.

\section{Regeneration of cellular metabolism and plant recovery after stress cessation are associated with both drought avoidance and drought tolerance strategies}

A regeneration of plant metabolism after the cessation of stress conditions refers mainly to the plant's ability to restore growth capacity and fresh biomass production (Luo 2010). The ability of the selected introgression forms, $\mathrm{BC}_{4}$-INT-40 and the $\mathrm{BC}_{4}$-INT-66, to recover was analyzed in all experimental conditions described earlier - in the field (Perlikowski et al. 2014), in tubes (Perlikowski et al. 2019), and in pots (Perlikowski et al. 2014, $2016 \mathrm{a}, \mathrm{b}$ ).

After 14 weeks of drought under the 'rainout shelters' in the field, both introgression forms differed significantly in the parameter of re-growth after subsequent re-watering (Fig. 1l). The $\mathrm{BC}_{4}$-INT-40 form revealed excellent and the $\mathrm{BC}_{4}$-INT-66 poor yield (Perlikowski et al. 2014). Resumption of watering had also a significant impact on regeneration of plant metabolism after $64 \mathrm{~d}$ of progressive drought in the tube system. Clear differences were observed between the $\mathrm{BC}_{4}$-INT- 40 and the $\mathrm{BC}_{4}$-INT-66 introgression forms. After the stress cessation, the introgression form $\mathrm{BC}_{4}$-INT-40 was characterized by a higher capacity to repair biological membranes (Perlikowski et al. 2014) and intensive new root development (Perlikowski et al. 2019). This trait might be associated with observed accumulation of primary metabolites in the root tissues after re-watering (Fig. $1 \mathrm{~m}$ ) (Perlikowski et al. 2019) and more efficient signaling in this genotype (Fig. 1n). A higher number of roots could significantly increase water uptake, which leads to increased transpiration and $\mathrm{CO}_{2}$ assimilation rate compared with the $\mathrm{BC}_{4}$-INT-66 form (Fig. 1o, Perlikowski et al. 2019). A higher photosynthetic rate of $\mathrm{BC}_{4}$-INT-40 form during recovery might be a reason for better re-growth capacity of this form (Fig. 1p) (Perlikowski et al. 2014).

After the stress cessation in pots, both introgression forms increased their RWC to the values observed before the initiation of drought stress. However, only the $\mathrm{BC}_{4^{-}}$ 
INT-40 form revealed the better ability to regenerate its biological membranes after rehydration, compared with the $\mathrm{BC}_{4}$ - INT-66 form (Perlikowski et al. 2014). This phenomenon could be partially associated with a higher accumulation of proline, melibiose, and galactaric acid on the $11^{\text {th }}$ day of water deficit in the $\mathrm{BC}_{4}$-INT-40 form (Fig. 1q) (Perlikowski et al. 2016a). Osmotic regulation is considered as one of the most important mechanisms of plant resistance to water deficit, and also could play a key role in the plant's ability to regenerate after stress cessation (Fig. 1q) (Morgan 1984). Other cellular alterations potentially involved in a greater capacity of $\mathrm{BC}_{4}$-INT-40 form to regenerate after re-watering, and to repair damaged cellular membranes, could be associated with membrane lipids (Fig. 1r) (Perlikowski et al. 2016b). Most of the chloroplast membrane lipids and many extra-chloroplast lipid species, as well as double bond index for most lipid classes, revealed a faster response to drought conditions in the $\mathrm{BC}_{4}$-INT-40 form compared the $\mathrm{BC}_{4}$-INT-66 form. These lipids started to increase their abundance on the third day of stress treatment in the $\mathrm{BC}_{4}$-INT-40 form and this could be associated with more efficient stress signaling pathways in that plant (Fig. 1k). Furthermore, after re-hydration, the $\mathrm{BC}_{4}$-INT-40 form showed a significant reduction of most chloroplast lipids, compared to the $11^{\text {th }} \mathrm{d}$ of drought ('lipidome turnover') (Fig. 1r). An effective stress signaling in the $\mathrm{BC}_{4}$-INT-40 form might refer also to a higher phosphatidylinositol and myo-inositol accumulation under the control and drought conditions (Perlikowski et al. 2016a,b). Myo-inositol and its derivatives are an important source of compounds used during the synthesis of a wide spectrum signaling molecules, including phosphatidylinositol (Liu et al. 2013, Zhai et al. 2015). Phosphatidylinositol is an important membrane component associated with stress signaling and regulation of cell metabolism in response to environmental factors, including soil water deficit (Xue et al. 2009).

Summarizing this part of the review, we conclude that the ability of plants to recover after stress cessation can significantly improve their capacity of drought resistance. This can be achieved by fast regeneration of cell metabolism and resumption of photosynthesis, which finally reflects in a higher yield production. Thus, with respect to prolonged severe drought conditions, this strategy of drought resistance can be crucial for plant survival.

\section{References}

Alvarez, S., Marsh, E.L., Schroeder, S.G., Schachtman, D.P.: Metabolomic and proteomic changes in the xylem sap of maize under drought. - Plant Cell Environ. 31: 325-340, 2008.

Bray, E.A., Bailey-Serres, J., Weretilnyk, E.: Responses to abiotic stresses. - In: Gruissem, W., Buchannan, B., Jones R. (ed.): Biochemistry and Molecular Biology of Plants. Pp. 1158-1249. American Society of Plant Physiologists, Rockville 2000.

Chaves, M.M., Zarrouk, O., Francisco, R., Costa, J.M., Santos, T., Regalado, A.P., Rodrigues, M.L., Lopes, C.M.: Grapevine under deficit irrigation: hints from physiological and molecular data. - Ann. Bot. 105: 661-676, 2010.

Dolferus, R.: To grow or not to grow: a stressful decision for plants. - Plant Sci. 229: 247-261, 2014.

Dos Reis, S.P., Lima, A.M., De Souza, C.R.B.: Recent Molecular Advances on downstream plant responses to abiotic stress. Int. J. mol. Sci. 13: 8628-8647, 2012.

Farooq, M., Wahid, A., Kobayashi, N., Fujita, D., Basra, S.M.A.: Plant drought stress: effects, mechanisms and management. Agron. Sustain. Dev. 29: 185-212, 2009.

Flexas, J., Bota, J., Loreto, F., Cornic, G., Sharkey, T.D.: Diffusive and metabolic limitations to photosynthesis under drought and salinity in C(3) plants. - Plant Biol. 6: 269-279, 2004.

Flexas, J., Medrano, H.: Drought-inhibition of photosynthesis in C3 plants: stomatal and non- stomatal limitations revisited. Ann. Bot. 89: 183-189, 2002.

Garczyński, S., Sokołowska-Garczyńska, K.: [Tolerance of durum wheat seedlings and mature plants to nitrogen and phosphorus deficiencies in the soil.] - Biuletyn IHAR 243: 47-56, 2007. [In Polish]

Golldack, D., Li, C., Mohan, H., Probst, N.: Tolerance to drought and salt stress in plants: unraveling the signaling networks. Front Plant Sci. 5: 151, 2014.

Humphreys, M.W., Thomas, H.: Improved drought resistance in introgression lines derived from Lolium-Multiflorum $\times$ Festuca-Arundinacea hybrids. - Plant Breed. 111: 155-161, 1993.

Kang, S.Z., Zhang, J.H.: Controlled alternate partial root-zone irrigation: its physiological consequences and impact on water use efficiency. - J. exp. Bot. 55: 2437-2446, 2004.

Kosmala, A., Perlikowski, D., Pawlowicz, I., Rapacz, M.: Changes in the chloroplast proteome following water deficit and subsequent watering in a high- and a low-droughttolerant genotype of Festuca arundinacea. - J. exp. Bot. 63: 6161-6172, 2012.

Lawlor, D.W.: Musings about the effects of environment on photosynthesis. - Ann. Bot. 103: 543-549, 2009.

Liu, X.X., Zhai, S.M., Zhao, Y.J., Sun, B.C., Liu, C., Yang, A.F., Zhang, J.R.: Overexpression of the phosphatidylinositol synthase gene $(Z m P I S)$ conferring drought stress tolerance by altering membrane lipid composition and increasing $\mathrm{ABA}$ synthesis in maize. - Plant Cell Environ. 36: 1037-1055, 2013.

Luo, L.J.: Breeding for water-saving and drought-resistance rice (WDR) in China. - J. exp. Bot. 61: 3509-3517, 2010.

Ma, W.M., Wei, L.Z., Long, Z.J., Chen, L.P., Wang, Q.X.: Increased activity of only an individual non-regulated enzyme fructose-1,6-bisphosphate aldolase in Anabaena sp strain PCC 7120 stimulates photosynthetic yield. - Acta Physiol. Plant. 30: 897-904, 2008.

McCue, K.F., Hanson, A.D.: Drought and salt tolerance - towards understanding and application. - Trends Biotechnol. 8: 358$362,1990$.

Morgan, J.M.: Osmoregulation and water-stress in higher-plants. - Annu. Rev. Plant Physiol. 35: 299-319, 1984.

Munns, R.: Comparative physiology of salt and water stress. Plant Cell Environ. 25: 239-250, 2002.

Perlikowski, D., Augustyniak, A., Masajada, K., Skirycz, A., Soja, A.M., Michaelis, A., Wolter, G., Kosmala, A.: Structural and metabolic alterations in root systems under limited water conditions in forage grasses of Lolium-Festuca complex. Plant Sci. 283: 211-223, 2019.

Perlikowski, D., Czyżniejewski, M., Marczak, L., Augustyniak, A., Kosmala, A.: Water deficit affects primary metabolism differently in two Lolium multiflorum/Festuca arundinacea introgression forms with a distinct capacity for photosynthesis and membrane regeneration. - Front. Plant. Sci. 7: 1063, 2016. Perlikowski, D., Kierszniowska, S., Sawikowska, A., Krajewski, 
P., Rapacz, M., Eckhardt, A., Kosmala, A.: Remodeling of leaf cellular glycerolipid composition under drought and re-hydration conditions in grasses from the Lolium-Festuca complex. - Front. Plant Sci. 7: 1027, 2016.

Perlikowski, D., Kosmala, A., Rapacz, M., Kościelniak, J., Pawlowicz, I., Zwierzykowski, Z.: Influence of shortterm drought conditions and subsequent re-watering on the physiology and proteome of Lolium multiflorum/Festuca arundinacea introgression forms, with contrasting levels of tolerance to long-term drought. - Plant Biol. 16: 385-394, 2014.

Schachtman, D.P., Goodger, J.Q.D.: Chemical root to shoot signaling under drought. - Trends Plant Sci. 13: 281-287, 2008.

Thomas, H., Humphreys, M.O.: Progress and potential of interspecific hybrids of Lolium and Festuca. - J. agr. Sci. 117: 1-8, 1991.

Uematsu, K., Suzuki, N., Iwamae, T., Inui, M., Yukawa, H.: Increased fructose 1,6-bisphosphate aldolase in plastids enhances growth and photosynthesis of tobacco plants. - J. exp. Bot. 63: 3001-3009, 2012.

Verslues, P.E., Agarwal, M., Katiyar-Agarwal, S., Zhu, J., Zhu, J.K.: Methods and concepts in quantifying resistance to drought, salt and freezing, abiotic stresses that affect plant water status. - Plant J. 46: 1092-1092, 2006.

Xue, H.W., Chen, X., Me, Y.: Function and regulation of phospholipid signalling in plants. - Biochem. J. 421: 145-156, 2009.

Yancey, P.H.: Organic osmolytes as compatible, metabolic and counteracting cytoprotectants in high osmolarity and other stresses. - J. exp. Biol. 208: 2819-2830, 2005.

Yu, B., Li, W., Comparative profiling of membrane lipids during water stress in Thellungiella salsuginea and its relative Arabidopsis thaliana. - Phytochemistry 108: 77-86, 2014.

Zhai, H., Wang, F.B., Si, Z.Z., Huo, J.X., Xing, L., An, Y.Y., He, S.Z., Liu, Q.C.: A myo-inositol-1-phosphate synthase gene, IbMIPS1, enhances salt and drought tolerance and stem nematode resistance in transgenic sweet potato. - Plant Biotechnol. J. 14: 592-602, 2016. 